\title{
Lateral Cephalometric Norms for Adolescent Kuwaitis: Soft Tissue Measurements
}

\author{
Rashed Al-Azemi ${ }^{a} \quad$ Badreia Al-Jame $^{\mathrm{b}} \quad$ Jon Årtun ${ }^{\mathrm{a}}$ \\ ${ }^{a}$ Department of Developmental and Preventive Sciences, Faculty of Dentistry, Kuwait University, and \\ ${ }^{b}$ Private practice, Northern Nuqra Medical Complex, Kuwait
}

\section{Key Words}

Lateral cephalograms - Soft tissue cephalometric norms •

Adolescents $\cdot$ Kuwaitis

\begin{abstract}
Objective: The purpose of this study was to establish lateral cephalometric soft tissue norms for adolescent Kuwaitis and to compare these norms to those of the common analysis systems. Subjects and Methods: Digital lateral cephalograms were made of 82 Kuwaiti boys and 80 Kuwaiti girls, of mean age $13.27 \pm 0.42$ and $13.21 \pm 0.43$ years, respectively, with almost ideal occlusion. Anatomic landmarks were identified directly on the digital images. Linear and angular measurements were calculated electronically using the Dolphin (version 9) software package. Results: The average subject in the sample had a smaller $\mathrm{Z}$ angle, a larger $\mathrm{H}$ angle, thicker soft tissue at point $A$ and the pogonion, and an increase in most measurements for lip protrusion when compared to the norms of the common analysis systems. The ranges of the majority of facial and labial parameters were larger than those reported in the above-mentioned norms. Gender differences were limited to upper lip length. Conclusion: Our findings suggest that Kuwaiti norms for lip protrusion should be used when making the extraction decision in adolescent Kuwaiti orthodontic patients. The larger than previously documented variation of the majority of soft tissue parameters suggests a need for establishing different norms for different facial types.

Copyright $\odot 2008$ S. Karger AG, Basel
\end{abstract}

\section{KARGER}

Fax +41613061234

E-Mail karger@karger.ch

www.karger.com
(C) 2008 S. Karger AG, Basel

1011-7571/08/0173-0215\$24.50/0

Accessible online at:

www.karger.com/mpp

\section{Introduction}

The need for lateral cephalometric analysis in orthodontic diagnosis and treatment planning is well established. The principle is that the radiographic measurements of each patient are compared with normative values. While small differences between the patient's measurements and the respective norms are interpreted as a normal variation, larger differences indicate structural deviations. A comprehensive cephalometric analysis must include an evaluation of positions, thicknesses and relationships of relevant soft tissue components. The soft tissue part of the analysis will assist the practitioner in determining whether or not the structural changes deemed necessary through the hard tissue analysis are likely to have a favorable effect on the facial profile, hence playing an important role in the extraction decision as well as in the decision whether or not to perform orthognathic surgery as part of the treatment.

Proposed soft tissue norms must reflect means and acceptable ranges of clinically meaningful measurements collected from a representative group of subjects to be valid as standards for comparison. Due to the soft tissue profile changes associated with growth and development [1-3], the subjects must be of relevant age, and previous findings suggest that gender differences should be explored $[1,3]$. Moreover, the samples should be limited to subjects with close to ideal occlusion to avoid bias due to effects of the differences in skeletal and dentoalveolar 
morphology on the soft tissue profile among subjects with different types of malocclusion $[4,5]$. Finally, the samples must be large enough to be representative of the population.

Adolescent soft tissue norms of the common lateral cephalometric analysis systems allow inferences only to white Americans [4-8]. While Burstone [4] and Merrifield [7] calculated means and ranges of cephalometric measurements on 32 [4] and 40 [7] untreated adolescents selected for optimal facial esthetics, the norms of Holdaway [5] and Ricketts [8] reflect subjective judgments based on their long clinical experience. The frequently used norm for lip positions relative to Steiner's proposed $S$ line appear to be based on one adolescent orthodontic patient selected for excellent post-treatment facial esthetics [6]. Accordingly, the above norms [4-8] are not based on inferences from large, representative groups of adolescents with natural development of almost ideal occlusion. We have demonstrated that the variation in skeletal and dentoalveolar relationships in such subjects is larger than previously documented [9]. A similar variation in soft tissue parameters may therefore not be unusual.

Studies comparing cephalometric measurements of different ethnic groups to the original norms $[10,11]$, as well as to each other [12-14], have been able to demonstrate ethnic differences of clinical significance, particularly in size and position of the nose [10,14], prominence and curvature of the lips $[10,14]$, configuration of the lower border of the nose relative to the upper lip [12, 14], thicknesses of the soft tissue covering the chin and dentoalveolar structures [11], and the length of the lips [12]. Among the few cephalometric evaluations of Arabs [12, 13, 15-17], two were limited to relatively small samples of adult Saudis without occlusal criteria strict enough to insure ideal occlusion $[12,16]$. Although the three remaining studies examined 90 adolescent Egyptians [13], 65 adolescent Jordanians [15] and 68 adolescent Kuwaitis [17], the inclusion criteria may not have been sufficient in limiting the samples to subjects with almost ideal occlusion, and the measures to insure representativity were not clearly stated. One article did not address soft tissue analyses [15], and the other included only few soft tissue parameters $[13,17]$.

The first settlers of Kuwait were Arabs from the Najd area of central Arabia $[18,19]$. Other early settlers included subjects of Persian origin as well as Arabs from various neighboring areas $[18,19]$. The immigration increased dramatically, concomitant with the expansion of the oil industry, before and after World War II. Education and trade during the following economic boom also resulted in immigration from East Africa, Asia, Europe and the USA through marriage to Kuwaitis [18, 19]. Cephalometric information on this ethnic mix is limited to an examination of adolescent orthodontic patients with deep bite and open bite malocclusions without considering soft tissue parameters [20], and a comparison of $68 \mathrm{Ku}-$ waiti adolescents to a similar group of white Americans, including only a few measurements, which have not been clearly defined, related to lip position [17]. The purpose of our study was to perform a lateral cephalometric evaluation of a large, representative group of 13- to 14-yearold Kuwaitis with close to ideal occlusion to establish cephalometric norms of clinically relevant soft tissue measurements for adolescent Kuwaiti orthodontic patients, and to make a clinical comparison between these norms and those of the common analysis systems.

\section{Subjects and Methods}

\section{Inclusion Criteria}

Kuwaiti nationals aged 13-14 years with no history of orthodontic treatment and almost ideal occlusion, defined as perfect intercuspation and posterior tooth alignment with no transverse discrepancies, no detectable lateral shift, an anterior shift of less than $2 \mathrm{~mm}$, no midline deviation, positive overjet of less than $3.5 \mathrm{~mm}$, positive overbite of less than two-thirds overlap of the maxillary to the mandibular incisors, arch length excess of less than $2 \mathrm{~mm}$ in either arch, and anterior tooth irregularity of less than $3.5 \mathrm{~mm}$ in either arch, were invited to participate in a lateral cephalometric examination.

\section{Determination of Sample Size}

A sample of 80 boys and 80 girls would allow a gender difference of $1.0 \mathrm{~mm}$ in the lower lip, to Ricketts' E plane, to be detected at an $\alpha$ of 0.05 and with a power of 99 . Interpretation of studies on frequency of malocclusion suggested that about $15 \%$ of 13 - to 14 -year-old Kuwaitis would meet the occlusal inclusion criteria $[21,22]$. To compensate for a lack of consent to participate, we therefore decided to screen about 800 of each gender. Following approval by the Ethics Committee of Kuwait University, Faculty of Dentistry, and authorization by the Research Department of the Kuwaiti Ministry of Education, the screening was performed during regular school hours, applying cluster sampling methods [23] when determining which school classes students should be screened from. The students in the public schools of each of the 6 administrative areas in Kuwait were defined as 6 different strata and the students in the different private schools as the 7th stratum. The students were informed about their rights to participate in the study, and each school principal provided a well-lit room for examination.

Sample

With written parental consent, 82 boys of mean age $13.27 \pm$ 0.42 years and 80 girls of mean age $13.21 \pm 0.43$ years, participated in the cephalometric analyses. Despite efforts at achieving 
population proportions among the subjects with almost ideal occlusion, subjects from Ahmadi, Jahra and the private schools were underrepresented in our sample, due to lack of compliance. However, considering the adequate size, the present sample may still allow valid inferences to adolescent Kuwaitis with almost ideal occlusion.

\section{Lateral Cephalograms}

Digital lateral cephalograms were made with the teeth in centric occlusion and the lips in relaxed contact at a focus/object distance of $150 \mathrm{~cm}$ and an object/receptor distance of $20 \mathrm{~cm}$ using a Planmeca Publication 688169 version 5 cephalostat (Planmeca OY, Helsinki, Finland). The subjects were placed in the headholder and asked to look straight ahead before adjusting the nasial positioner, with a built-in millimeter scale.

\section{Measurements on Lateral Cephalograms}

Anatomic landmarks as well as the 0 - and 2-cm markings on the ruler were identified directly on the digital computer images (fig. 1). Linear and angular measurements were calculated electronically using the Dolphin version 9 software package (Dolphin Imaging and Management Solutions, Chatsworth, Calif., USA), as well as adjusting linear readings to the actual subject dimensions.

\section{Error of the Method}

The reproducibility of the measurements was assessed by statistically analyzing the differences between double measurements taken at least 1 week apart on 20 randomly selected cephalograms. The error was calculated from the equation:

$$
S_{x}=\sqrt{\frac{\sum D^{2}}{2 N}}
$$

where $\mathrm{D}$ is the difference between duplicated measurements and $\mathrm{N}$ is the number of double measurements [24]. The errors ranged from $0.26\left(\mathrm{Li}-\mathrm{H}\right.$ line) to $0.71\left(\mathrm{Pg}^{\prime}-\mathrm{Pg}\right)$ for the linear measurements. The errors for the angular measurements ranged from 0.48 $\left(\mathrm{N}^{\prime} \mathrm{Pg}^{\prime} / \mathrm{FH}\right)$ to 0.75 ( $\mathrm{Z}$ angle), with the exception of the error for $\mathrm{CmSnLs}$, which was 2.09. Pearson's $\mathrm{R}$ between respective 1 st and 2nd measurements were all $>0.74(\mathrm{p}<0.001)$.

\section{Data Analyses}

Descriptive statistics were performed, and Student's t tests were employed to test for gender differences. Bonferroni corrections were carried out to reduce the possibility of significances due to chance, by considering $\mathrm{p}$ values less than the corresponding Bonferroni correction values as significant [25]. Sample means, standard deviations and ranges of each respective linear and angular measurement were interpreted as lateral cephalometric norms for adolescent Kuwaitis. Separate norms were calculated for boys and girls regarding parameters demonstrating gender differences. Pair-wise comparisons were made between the Kuwaiti norms and the respective norms of the common analysis systems [4-8] (table 1), following multiplying the linear norms by 0.92 to adjust for the $8 \%$ magnification [4-8] (table 1). A difference of $2^{\circ}$ or $2 \mathrm{~mm}$ was considered clinically significant, with the exception that a difference of $1 \mathrm{~mm}$ was considered clinically significant for linear dimensions with norms less than $10 \mathrm{~mm}$ (table 1).

Lateral Cephalometric Norms for Adolescent Kuwaitis

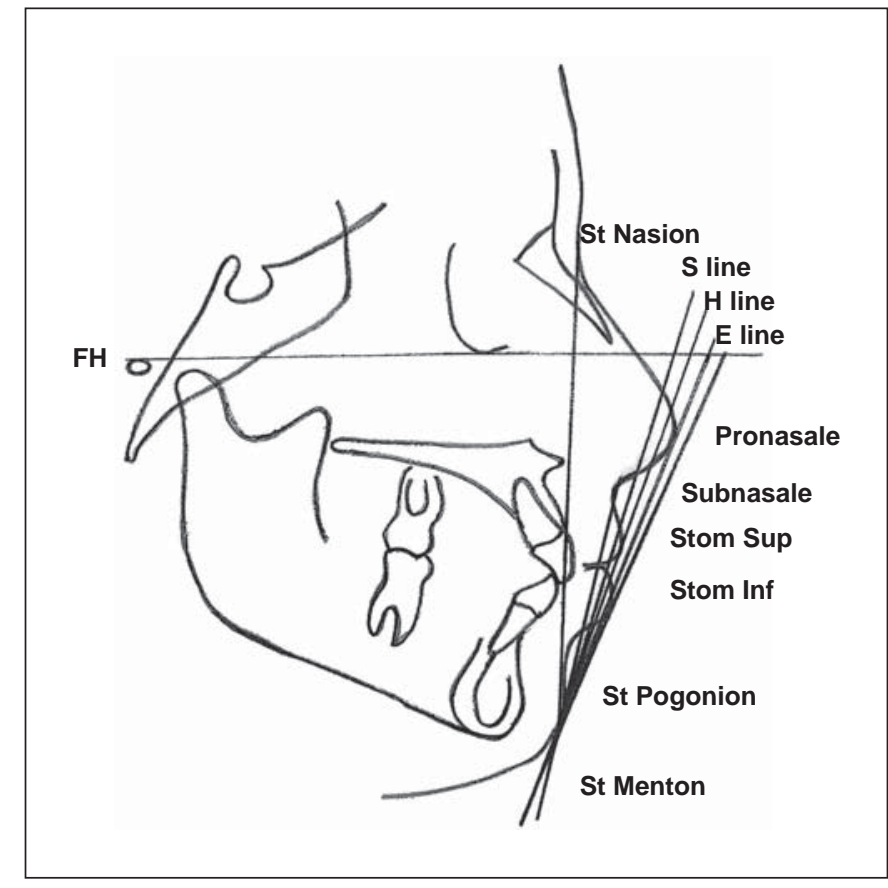

Fig. 1. Cephalometric tracing of an average subject in the sample, indicating identification of landmarks and reference lines. St = Soft tissue; soft tissue nasion = soft tissue profile's most concave point at the bridge of the nose; pronasale = point of the anterior curve of the nose; subnasale $=$ point where the nose connects to the center of the upper lip; soft tissue A point = most concave point between subnasale and the anterior point of the upper lip; stomion superius = most inferior point on the curve of the upper lip; stomion inferius $=$ most superior point on the curve of the lower lip; soft tissue pogonion = point on the anterior curve of soft tissue chin; soft tissue menton = the most inferior point of the soft tissue chin; $\mathrm{FH}=$ Frankfort horizontal line.

\section{Results}

\section{Facial Norms}

Merrifield's Z angle was clinically smaller and Holdaway's $\mathrm{H}$ angle clinically larger than the published norms. However, the distances from the pronasale to soft tissue point $\mathrm{A}$ and to subnasal were clinically similar to the norms of Holdaway and Burstone. The increased ranges of all anteroposterior angular and linear parameters relative to the respective ranges were considered clinically significant (table 1).

\section{Labial Norms}

With exception of the position of labrale superius relative to Steiner's S line and relative to soft tissue point A according to Holdaway, all measurements for lip protru- 
Table 1. Means, standard deviations (SD) and ranges (min. and max.) of lateral cephalometric parameters with and without significant gender differences of 82 Kuwaiti boys and 80 Kuwaiti girls with almost ideal occlusion (Kuwaiti norms), and similar parameters from the respective original articles (published norms) on the common lateral cephalometric analysis systems (references)

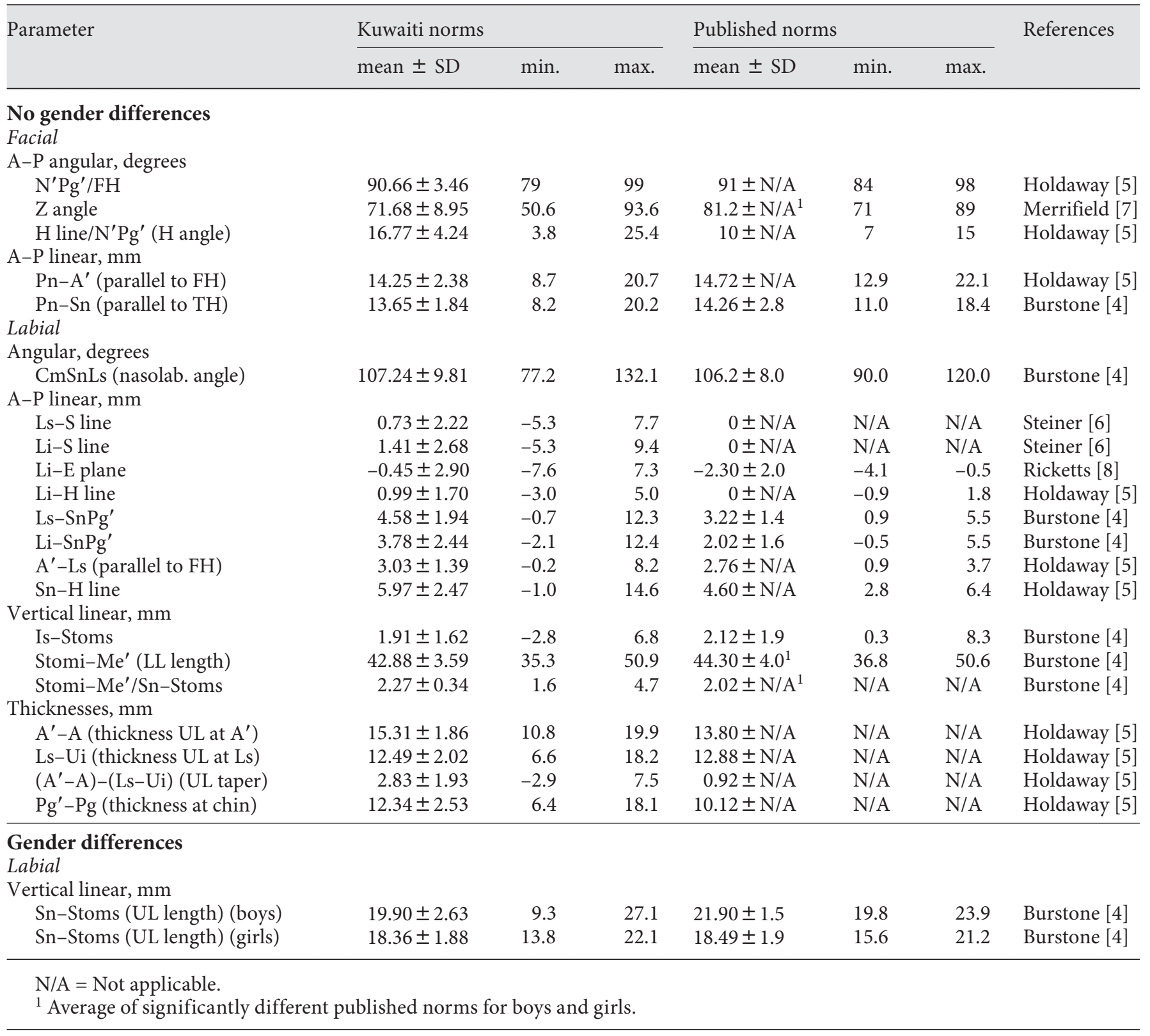

sion were clinically larger than the published norms (table 1). While the soft tissue thickness at incision superius was clinically similar to the norms, the soft tissue coverage was clinically larger at point $A$ and pogonion, and the lip taper was clinically larger than the norm of Holdaway (table 1).
The only significant difference in lip lengths was that the boys had a shorter upper lip than the published norms (table 1). With the exceptions of the linear dimensions incision superius-stomion superius and stomion inferius-menton the ranges of all labial norms were clinically larger than the respective ranges available in the analysis systems (table 1). 


\section{Gender Differences}

Following the Bonferroni correction, gender differences were only detected in the linear dimension subnasale-stomion superius, with the average boy having a 1.54-mm-longer upper lip $(\mathrm{p}<0.01$; table 1$)$.

\section{Discussion}

Due to the obvious difficulties associated with identifying subjects representing the different ethnic backgrounds of Kuwaitis, our sampling was designed to identify a large subject group representative of the ethnic mix. Our findings may therefore not allow inferences to direct descendents of the different Middle Eastern ethnic subgroups.

Lack of samples of similar representativity from different ethnic groups precluded the use of statistical analyses for testing of ethnic differences. Besides, such studies may be considered of minor clinical significance. Our purpose was to establish valid soft tissue cephalometric norms for adolescent Kuwaitis at ages when optimal onephase comprehensive orthodontic treatment normally commences, and to test whether such norms are needed for appropriate clinical decision-making. In keeping with our paper on hard tissue norms [9], we therefore made the general consideration that mean value differences of at least $2 \mathrm{~mm}$ or $2^{\circ}$ were large enough to justify the use of population-specific norms for Kuwaitis, rather than comparing to the norms presented in the common analyses systems. However, when judging normative values smaller than $10 \mathrm{~mm}$ for lip position and thickness, we considered a difference of $1 \mathrm{~mm}$ to indicate a need for use of Kuwaiti norms. We adjusted all published and own linear norms for magnification to avoid erroneous determination of clinical significances.

The finding that the soft tissue facial angle was similar to Holdaway's norm supports our previous finding of clinically similar hard tissue facial angle compared to the norm of Downs [9]. The finding that the $\mathrm{Z}$ angle was clinically smaller than the norms of Merrifield and that Holdaway's $\mathrm{H}$ angle was clinically larger suggest that $\mathrm{Ku}-$ waiti adolescents have a clinically significant increase in lip protrusion compared to white Caucasians. Minimal difference in soft tissue thickness of the upper lip at the level of the incisor prominence suggests that the underlying reason is increased convexity of the soft tissue profile, and may support our finding of similar convexity in hard tissue profile [9] as well as a recent study comparing 68 adolescent Kuwaitis to a matched group of white Americans [17].

Lateral Cephalometric Norms for

Adolescent Kuwaitis
In keeping with a recent study [17], our findings suggest that adolescent Kuwaitis have increased lip protrusion relative to the norms for white Caucasians. The underlying reason for this difference may be increased incisor protrusion, indirectly supporting our previous findings [9], since we failed to detect any differences in nose prominence and lip thickness at the level of the incisors (table 1). Our finding of increased soft tissue thickness at the pogonion in Kuwaitis (table 1) may increase the confidence of that interpretation. Our finding of clinically similar superior sulcus depth in adolescent $\mathrm{Ku}$ waitis compared to Holdaway's for white Caucasians may be explained by the increase in thickness of the upper lip at point $\mathrm{A}$ (table 1 ).

We could not confirm Merrifield's finding of a larger $\mathrm{Z}$ angle in boys than girls, and Burstone's finding that boys have longer lower lips. While our findings do suggest gender differences in upper-lip length, the actual difference was smaller than the limit we set for clinical significance, reducing the clinical need for gender-specific norms for that dimension in adolescent Kuwaitis (table 1). We documented a clinically larger lip taper in adolescent Kuwaitis than in white Caucasians. Holdaway suggests a lip taper of $1 \mathrm{~mm}$ in subjects with relaxed, competent lips, regardless of incisor compensation for skeletal discrepancies [5]. The large variation in lip taper among the subjects in our sample with ideal occlusion and relaxed lip position, compared with our previous finding of a large variation in incisor inclination [9], may be used to challenge that concept.

It should be stressed that our soft tissue facial and labial norms only apply to adolescent Kuwaitis with skeletal relationships close to the normative values. Our findings show that the variation of most facial and labial parameters in adolescent Kuwaitis is clinically larger than previously suggested for white Caucasians. Accordingly, attempts should be made at exploring the need for establishing different soft tissue norms for different patterns of skeletal morphology.

Clinicians frequently recommend combined orthodontic and surgical treatment as the optimal option in patients with large skeletal discrepancies. We challenged that concept in a previous communication [9] since this population-based sample of adolescent Kuwaitis with almost ideal occlusion have an unusually large variation in skeletal relationships. However, if certain extremes in skeletal patterns are associated with unesthetic soft tissue positions or relationships, such recommendations may be justified. Accordingly, attempts should be made at exploring how patients, parents, the laity, and members of 
the dental profession perceive facial esthetics in subjects with different soft tissue relationships and positions despite ideal occlusion.

\section{Conclusions}

Our findings suggest that Kuwaiti norms for lip protrusion should be used when making the extraction decision in adolescent Kuwaiti orthodontic patients. The larger than previously documented variation of the majority of the soft tissue parameters suggests a need for establishing different norms for different facial types.

\section{Acknowledgements}

This research was supported by Kuwait University grant No. DD07/00.

\section{References}

1 Nanda RS, Meng H, Kapila S, Goorhuis J: Growth changes in the soft tissue facial profile. Angle Orthod 1990;60:177-190.

-2 Bishara SE, Jakobsen JR, Hession TJ, Treder JE: Soft tissue profile changes from 5 to 45 years of age. Am J Orthod Dentofacial Orthop 1998;114:698-706.

3 Thilander B, Persson M, Adolfsson U: Roentgen-cephalometric standards for a Swedish population. A longitudinal study between the ages of 5 and 31 years. Eur J Orthod 2005; 27:370-389.

4 Burstone CJ: Lip posture and its significance in treatment planning. Am J Orthod 1967;53: 262-284.

5 Holdaway RA: A soft-tissue cephalometric analysis and its use in orthodontic treatment planning. Part 1. Am J Orthod 1983;84:128.

6 Steiner CC: The use of cephalometrics as an aid to planning and assessing orthodontic treatment. Report of a case. Am J Orthod 1960;46:721-735.

7 Merrifield LL: The profile line as an aid in critically evaluating facial esthetics. Am J Orthod 1966;52:804-822.

8 Ricketts RM: Perspectives in the clinical application of cephalometrics. The first fifty years. Angle Orthod 1981;51:115-150.

-9 Al-Jame B, Årtun J, Al-Azemi R, Behbehani F: Lateral cephalometric norms for adolescent Kuwaitis: hard tissue measurements. Med Princ Pract 2006;15:91-97.
10 Alcalde RE, Jinno T, Orsini MG, Sasaki A, Sugiyama RM, Matsumura T: Soft tissue cephalometric norms in Japanese adults. Am J Orthod Dentofacial Orthop 2000;118:8489.

11 Basciftci FA, Uysal T, Buyukerkmen A: Determination of Holdaway soft tissue norms in Anatolian Turkish adults. Am J Orthod Dentofacial Orthop 2003;123:395-400.

12 Shalhoub SY, Sarhan OA, Shaikh HS: Adult cephalometric norms for Saudi Arabians with a comparison of values for Saudi and North American Caucasians. Br J Orthod 1987;14:273-279.

13 Bishara SE, Abdalla EM, Hoppens BJ: Cephalometric comparisons of dentofacial parameters between Egyptian and North American adolescents. Am J Orthod Dentofacial Orthop 1990;97:413-421.

14 Hwang H-S, Kim W-S, McNamara JA Jr: Ethnic differences in the soft tissue profile of Korean and European-American adults with normal occlusion and well balanced faces. Angle Orthod 2002;72:72-80.

15 Hamdan AM, Rock WP: Cephalometric norms in an Arabic population. J Orthod 2001;28:297-300.

16 Hassan AH: Cephalometric norms for Saudi adults living in the western region of Saudi Arabia. Angle Orthod 2006;76:109-113.
17 Behbehani F, Hicks EP, Beeman C, Kluemper GT, Rayens MK: Racial variations in cephalometric analysis between whites and Kuwaitis. Angle Orthod 2006;76:406-411.

18 Ismael JS: Kuwait: Social Change in Historical Perspective, ed 1. New York, Syracuse University Press, 1982.

19 Royal Scottish Museum: The Evolving Culture of Kuwait. Edinburgh, Her Majesty's Stationary Office, 1985.

20 Loufty MS: Cephalometric evaluation of deep overbite and anterior open bite in $\mathrm{Ku}$ wait school children. Trans Eur Orthod Soc 1973;281-285.

21 Al-Emran S, Wisth PJ, Bøe OE: Prevalence of malocclusion and need for or thodontic treatment in Saudi Arabia. Community Dent Oral Epidemiol 1990;18:253-255.

22 Proffit WR: The prevalence of malocclusion and orthodontic treatment need in the United States: estimates from the NHANES III survey. Int J Adult Orthod Orthognath Surg 1998;13:97-106.

23 Cochran WG: Sampling Techniques, ed 3. New York, Wiley, 1977.

24 Dahlberg G: Statistical Methods for Medical and Biological Students. London, Allen \& Unwin, 1940, pp 122-132.

25 Woodward M: Epidemiology: Study Design and Data Analysis, ed 2. New York, Chapman \& Hall/CRC, 2004, p 437. 